Article

\title{
Bone Substitutes Scaffold in Human Bone: Comparative Evaluation by 3D Micro-CT Technique
}

\author{
Rossella Bedini ${ }^{1}$, Raffaella Pecci ${ }^{1, *(1)}$, Deborah Meleo ${ }^{2}$ and Ilaria Campioni ${ }^{3}(\mathbb{C}$ \\ 1 National Centre of Innovative Technologies in Public Health, Istituto Superiore di Sanità, 00161 Rome, Italy; \\ rossella.bedini@iss.it \\ 2 Private Dental Practitioner, 00161 Rome, Italy; deborah.meleo@gmail.com \\ 3 Independent Researcher, 00161 Rome, Italy; ilaria.campioni@gmail.com \\ * Correspondence: raffaella.pecci@iss.it; Tel.: +39-06-49902027
}

Received: 15 April 2020; Accepted: 14 May 2020; Published: 16 May 2020

\begin{abstract}
The main purpose of the study is to assess a selection of commercially available bone biomaterials substitutes used as scaffolds for tissue engineering applications in dentistry, performing a clinical study on human subjects and using the microcomputed tomography (micro-CT) analysis to investigate the main morphological and critical parameters of bone and biomaterials structures. Micro-CT was performed in both the phases, preclinical and clinical. In addition, it was combined with histology to analyze the extracted bone four months after implantation. Quantitative analysis of the main morphological parameters as the porosity, the bone volume fraction (BV/TV) and the trabecular thickness (Tb.Th) evidenced the main difference among the biomaterials properties and their influence on the bone tissue regeneration. Qualitative observations by the three-dimensional (3D) reconstruction of the microstructure, contributed to the visualization of the mineralized areas. The analyses conducted on the bone substitutes before and after the implantation allowed quantifying the main biomaterials morphological parameters and the characterization of the human bone tissue regeneration. Thus, micro-CT and its combined application with histology demonstrated as a powerful approach for the microstructural investigation and for the final assessment of the efficacy and effectiveness of the various treatments and implants.
\end{abstract}

Keywords: biomaterials; bone substitute; human bone; scaffold; microcomputed tomography

\section{Introduction}

The restoration of the continuity and integrity of skeletal segments, altered or damaged due to congenital dysmorphisms, inflammatory and tumor pathologies or trauma, represents a challenge for orthopedists and oral-maxillofacial surgeons. In particular, in the dental field, a bone condition unfavorable to the prosthetically guided placement of the implants could complicate the implant-prosthetic rehabilitation treatment. Bone deficiencies can be solved using numerous grafting biomaterials, currently available on the market. Despite the progress made by scientific research and the continuous evolution of surgical techniques for bone augmentation, the simulation of the natural behavior of bone, which is the principal object of tissue engineering, is not easy to obtain, considering the multifunctional properties of the natural bone, i.e., nature self-repairing, remodeling and regeneration [1].

The ideal bone grafting material should have characteristics such as biocompatibility and biotolerability, absence of carcinogenicity and teratogenicity, non-antigenicity and affordability. Moreover, it should be bioresorbable, hydrophilic, easy to use and manipulate, non-toxic, with excellent biomechanical characteristics, sterile or sterilizable and it has not to act as a substrate for the proliferation of pathogenic microorganisms [2,3]. Bioactivity, i.e., the ability to stimulate the production 
of new bone through the mechanisms of osteogenesis, osteoinduction and osteoconduction is another important aspect.

As evidenced in a recent review [4], the requirements in terms of scaffold composition, characteristics, and design, should be defined considering many aspects, like the specific clinical bone deficiency, the patient characteristics, the defect and the desired outcome. Furthermore, it is underlined that scaffolds structures need to be controlled not only on a macroscopic level but also microscopically, to improve the main features.

In the last years, many studies were elaborated considering in vitro and in vivo applications and scaffolds of various compositions looking for the best reasonable solution [5].

The manufacturing technologies for scaffolds are numerous from the conventional ones like solvent casting and particle leaching [6], freeze-drying [7], freeze-gel casting [8], powder-forming [9], sol-gel $[10,11]$ and electrospinning [10], to the emerging ones as bioprinting [12] and three dimensional (3D) printing [13-16].

The design and the characterization of scaffolds benefit from the advantages offered by microcomputed tomography (micro-CT) analysis in particular in relation to the morphometric structural investigation, to quantify scaffold porosity, surface area, pore size, pore distribution and structural thickness, allowing a precise measurement of bone growth $[2,17,18]$. Unsintered hydroxyapatite/poly-D/L-lactide (3D-HA/PDLLA) with beta-tricalcium phosphate (b-TCP) [19] or with mesenchymal stem cell [20], dental pulp stem cells [21], amniotic epithelial cells loaded on a calcium-phosphate synthetic bone substitute [22] and polycaprolactone-tricalcium phosphate (PCL-TCP) [23], are some examples of bone grafts compositions studied by the application of microtomographic analysis. Moreover, studies were carried out on bioactive composite 3D scaffolds [24] and degradable hybrid polymer biomaterials with controlled properties for highly efficient biomedical applications [25].

The micro-CT is a consolidated 3D nondestructive imaging technology used for various applications and specifically for the analysis of bone structures and mineralized tissue [26,27]. Dentistry, maxillofacial surgery and orthopedics are the main fields of interest, and in the last years, more are emerging regarding new manufacturing processes and quality controls for medical applications $[16,28]$. The possibility to obtain information about bone tissue $[26,29,30]$ and other materials microarchitecture and composition, depends on the accuracy of the analysis in all the steps, from the specimen preparation to the settings of the appropriate parameters during the acquisition and reconstruction of the images. Actually, some limitations of its adoption are related to the cost of the analysis. During the last decade, the cost-effectiveness is improved particularly due to the availability of more computing power at a lower cost.

In previous works [31-33], preliminary evaluations were carried out considering the application of some bone substitutes on patients. Despite the limitations, those studies allowed the validation of the micro-CT based methodology for the analysis and the clinical procedure.

Thus, the purpose of the study was to extend the preliminary part of the clinical study and the partial evaluations, carrying out a complete assessment of six commercially available bone biomaterials substitutes used as scaffolds for tissue engineering applications by using microtomographic analysis as the main methodology for the investigation in all the phases of the study. The micro-CT was applied in the preclinical phase for the evaluation of the selected scaffolds, before and then after the implantation, to determine the bone and biomaterials morphological parameters, to characterize the normal human bone tissue combined with histology and to finally assess the efficacy of the various treatments and implants. 


\section{Materials and Methods}

\subsection{Biomaterials}

The choice of the biomaterials was made according to their origin and the possibility of finding on the market formulations available in various dimensions and shapes (blocks, chips or granular). In total, six different materials, widely used in several bone regeneration procedures in oral surgery, were considered:

- Inorganic bovine bone (Bio-Oss ${ }^{\circledR}$, Geistlich, Wolhusen, Switzerland);

- Dehydrated and deantigenated equine bone (Bio-Gen ${ }^{\circledR}$, Biotek Srl, Milano, Italy);

- $\quad$ Reabsorbable nano-hydroxyapatite (HA; Apagen Resorb 400, Gruppo Stomygen Srl, Roma, Italy);

- $\quad$ Porous hydroxyapatite based (ENGIpore ${ }^{\circledR}$, Finceramica, Faenza, Italia);

- $\quad$ Tricalcium phosphate (TCP; Bioset, Tiradix Srl, Vimercate, Italy);

- $\quad$ PLA/PGA copolymer-based bone filling material (SINTbone, Ghimas Spa, Bologna, Italia).

Three of them-Bio-Gen ${ }^{\circledR}$, Bioset and Apagen Resorb 400-were already investigated in the preliminary evaluation, the first part of the clinical study (Part 1) [31], and they were here assessed using different technique for analyzing some aspects, repeating the morphological analysis, in order to take into account the updated settings. Indeed, further investigations were developed in the second part of the clinical study (Part 2) with other settings. Partial micro-CT examinations were initially carried out for the materials Bio-Oss ${ }^{\circledR}$ and ENGIpore ${ }^{\circledR}$ [33] and they are here reported for a better comparison among all the samples. Moreover, a dehydrated and deoxygenated human Iliac Crest Bone block (ICB), was considered in order to acquire morphometric reference parameters for the evaluations during the preclinical phase. The investigations related to the clinical study were referred to the specific bone site after the spontaneous healing. Details of all the materials organized in four groups and classified in Part 1 and Part 2 are summarized in Table 1.

Table 1. Biomaterials selected for the study.

\begin{tabular}{cccccc}
\hline Clinical Study & Groups & Label & Commercial Name & Origins and Description & Dimensions (mm) \\
\hline Part 2 & 1-Bio-bone & la & Bio-Oss ${ }^{\circledR}$ & $\begin{array}{c}\text { Animal } \\
\text { Bovine bone, Block } \\
\text { Animal }\end{array}$ & $13.3 \times 9 \times 6.5$ \\
Part 1 & & 1b & Bio-Gen ${ }^{\circledR}$ & Equine bone, Block \\
Synthetic \\
Part 1
\end{tabular}

\subsection{Micro-Computed Tomography Analysis}

3D Micro-CT scans were performed using a desktop scanner (SkyScan 1072; Bruker microCT, Kontich, Belgium). The software NRecon (v1.7.0; Bruker microCT, Kontich, Belgium), was used to reconstruct the cross-section images of the objects. The application 3D Creator (v2.5, Bruker microCT, Kontich, Belgium) was used for the rendering of the 3D models reconstructed. The software CT-Analyser (v1.16; Bruker microCT, Kontich, Belgium) elaborated the morphometric parameters.

The main acquisition parameters were the following ones: source voltage $100 \mathrm{kV}$, source current $98 \mu \mathrm{A}$, rotation step $0.45^{\circ}$, rotation angle $180^{\circ}$ and $1 \mathrm{~mm}$ aluminum filter. Specific settings were used for the acquired biomaterials in preclinical and clinical phases.

In the preclinical phase the micro-CT resolution, for each specimen scanned and according to the labels defined in Table 1, was $11.72 \mu \mathrm{m}$ for $1 \mathrm{a} ; 13.32 \mu \mathrm{m}$ for $1 \mathrm{~b} ; 7.32 \mu \mathrm{m}$ for $2 \mathrm{~b} ; 3.66 \mu \mathrm{m}$ for $3 \mathrm{a} ; 11.72 \mu \mathrm{m}$ 
for $4 \mathrm{a}$ and $16.30 \mu \mathrm{m}$ for ICB. The values take into account that the biomaterials are commercially available in various dimensions.

In the clinical phase, in order to allow the overlapping of the results and quantities obtained, all the samples were scanned with the same acquisition settings previously declared and an image pixel size of $3.1 \mu \mathrm{m}$. For the reconstruction step, three density ranges were defined and three different colors were assigned to discriminate within each sample, structures of different radiopacity, such as newly formed bone tissue in different stages of mineralization and the biomaterials used.

\subsection{Preclinical Phase}

This phase is preliminary to the application in the human model. Initial morphometric characteristics of the selected materials, including also the biomaterials $1 \mathrm{~b}$, and $3 a$ (Part 1 ) as indicated and labeled in Table 1, were acquired by micro-CT. The Apagen 400 Resorb-2a, which does not have a solid formulation large enough to allow pre-implant morphometric evaluations was excluded as in the preliminary study [31]. In this preclinical phase, the blocks of the biomaterials were considered in the various dimensions commercially available. Furthermore, morphometric parameters were elaborated considering as a reference, the ICB sample.

\subsection{Clinical Phase}

Scaffolds of the selected materials (1a, 2b, 4a, ICB-Table 1) with a smaller dimension of ones used for the preclinical validation, chips or granules of $0.5-1 \mathrm{~mm}$, were implanted in a human model of a primary bone defect as a post-extraction site. For this part-Part 2-of the clinical study, three patients were enrolled, aged between 18 and 30 and in good health, who needed bilateral surgical extraction of the lower third molars. The same methodology, already validated for the other three patients (Part 1) and partially for the specimens $1 \mathrm{a}$ and $2 \mathrm{~b}$, was applied [31,33].

All the human subjects selected gave their informed consent for the inclusion and before starting the study that was conducted in accordance with the Declaration of Helsinki, and the protocol was approved by the Ethics Committee of Sapienza University of Rome, Policlinic hospital Umberto I in Rome, (Rif.2134/28.04.2011).

The initial surgical procedure provided the execution of an intrasulcular bayonet-shaped mucoperiosteal flap after truncal anesthesia to the lower alveolar with $3 \%$ mepivacaine, without vasoconstrictor and infiltrative with $2 \%$ mepivacaine and vasoconstrictor. The residual bone cavity was carefully overhauled, in order to eliminate any inflammation tissue present, and washed with sterile physiological solution. At this point in each patient, one side was sutured and healed simply by the formation of the clot (implant site, control), while the other (implant site, test) was grafted with one of the selected biomaterials. The bone substitute was compacted inside the post-extraction alveolus and protected on the surface by the application of a collagen sponge Condress (Abiogen Pharma SpA, Pisa, Italy). The flaps were closed in their original position, therefore for the first intention, by the application of a suture in Ethilon 4.0 (Johnson \& Johnson, Somerville, NJ, USA) to the detached points.

At the end of all the interventions, antibiotic therapy (amoxicillin + clavulanic acid $1 \mathrm{~g}, 2$ times a day for 5 days) and pain relief (nimesulide $500 \mathrm{mg}$, 2 times a day for 3 days) were prescribed to the patients and it was suggested to them to rinse, 2 times a day and for a week, with $0.2 \%$ chlorhexidine based mouthwash.

Suture removal was performed on the seventh day for the control side and on the fourteenth day for the test side. Sixteen weeks after the avulsive event, after infiltrative local anesthesia with $2 \%$ mepivacaine with vasoconstrictor, a full-thickness linear extraction was made at the level of the trine and intrasulcular on the seventh. After removing the mucoperiosteal flap thus drawn, the samples were taken with trephine burs in surgical steel and with an internal diameter of $3 \mathrm{~mm}$ (Drill-300, FMD Srl. Medical Devices, Italy) mounted on the contra-angle handpiece and under abundant cooling. Specimens of a diameter of $3 \mathrm{~mm}$ and height of approximately $5 \mathrm{~mm}$ were obtained, which were immediately placed in formalin and sent for microtomographic and histological tests. 
Before the microtomographic acquisition, each specimen was washed with a physiological solution and it was fixed on the appropriate support. After completing the scan, the carrot was again immersed in a sterile physiological solution for about ten minutes to facilitate rehydration and subsequently in formalin for storage and for histological examination.

For each pair of specimens (nomenclature "label test/control"), also for the ones implanted in Part 1 , the morphometric parameters were calculated and two-dimensional (2D) and 3D images, as well as 3D models, were elaborated.

The flow diagram of the clinical study is illustrated in Figure 1.

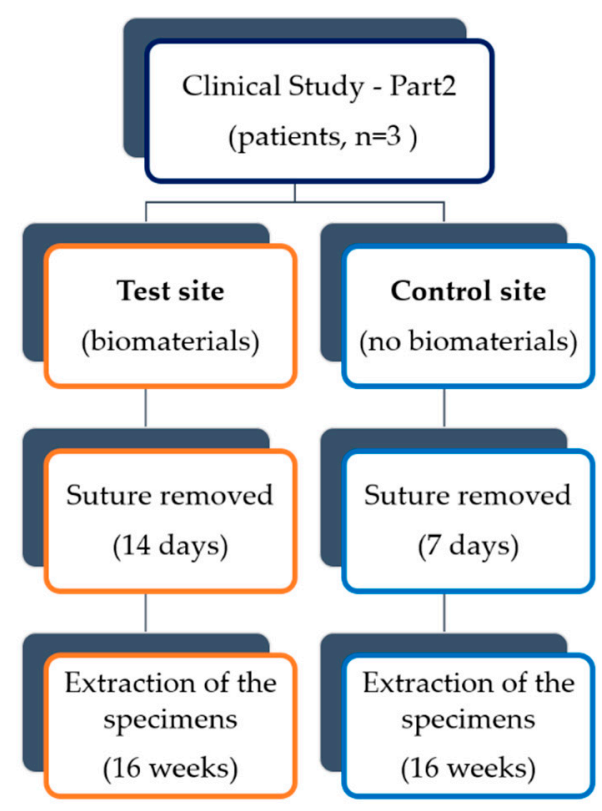

Figure 1. Flow chart of the clinical study.

\subsection{Hystology}

The bone fragments extracted after 4 months, for Part 2 of the clinical study and similarly as for Part 1, were subsequently included in resin, and treated according to the traditional procedures for the preparation of tissues for histological analysis (non-decalcified samples, staining with hematoxylin and eosin, 100× magnification). A comparison among control and test specimens was carried out.

\section{Results}

Acquired 2D images slices of each biomaterial sample and all the extracted specimens of the implants, including the ones of the preliminary clinical study [31,33], were elaborated in order to perform the morphological analysis and to define the 3D reconstructed models.

The morphometric parameters acquired, represent the percentage volume-bone volume fraction (BV/TV) in \%; the specific surface examined-specific bone surface (BS/BV) in $\mathrm{mm}^{-1}$; the percentage of empty spaces with respect to the total volume-porosity in \%; the thickness of the trabecular bones-trabecular thickness ( $\mathrm{Tb}$. Th) in $\mu \mathrm{m}$ and the distance between the trabeculae-trabecular separation (Tb.Sp) in $\mathrm{mm}^{-1}$.

The main morphological results for the selected biomaterials, and for the ICB, investigated in the preclinical phase before the implantation, are indicated in Table 2. 
Table 2. Morphological parameters of the biomaterials selected before the implantation.

\begin{tabular}{ccccccc}
\hline Group & Label & $\begin{array}{c}\text { BV/TV } \\
(\mathbf{\%})\end{array}$ & $\begin{array}{c}\text { BS/BV } \\
\left(\mathbf{m m}^{-1}\right)\end{array}$ & Porosity (\%) & $\begin{array}{c}\text { Tb.Th } \\
(\boldsymbol{\mu m})\end{array}$ & $\begin{array}{c}\text { Tb.Sp } \\
\left(\mathbf{m m}^{-\mathbf{1}}\right)\end{array}$ \\
\hline 1-Bio-bone & 1a & 28.73 & 18.30 & 71.27 & 0.22 & 0.51 \\
2-HA & 1b & 26.59 & 14.05 & 73.41 & 0.27 & 0.68 \\
3-TCP & 3a & 31.69 & 23.88 & 68.31 & 0.16 & 0.47 \\
$\begin{array}{c}\text { 4-polymer } \\
\text { Iliac crest } \\
\text { bone }\end{array}$ & 4a & 24.13 & 11.09 & 75.87 & 0.28 & 0.52 \\
\hline
\end{tabular}

Among the synthetic derivatives (Table 1), the biomaterial that resulted in being most similar to human bone, in particular in reference to the ICB values of porosity and BV/TV, turned out to be the ceramic hydroxyapatite ( $2 \mathrm{~b}$, Table 2). Nevertheless, variations are relevant for the BS/BV and the $\mathrm{Tb}$.Th, which is noticeably different, $0.16 \mu \mathrm{m}$ with respect to the ICB value of $0.31 \mu \mathrm{m}$.

At the end of the in-vitro microtomographic experimentation, 3D images of selected parts of the specimens were defined in order to better display the interconnectivity of the structures observed, Figure 2. The negative coloring used allowed underling the connectivity density, i.e., the presence of communication spaces and connections among the porosities. The three products ( $1 \mathrm{a}, 1 \mathrm{~b}$ and ICB), showed a higher interconnection among the internal empty spaces (Figure $2 \mathrm{~A}-\mathrm{C}$ ) compared to the other materials (2b, 3a and $4 a)$.
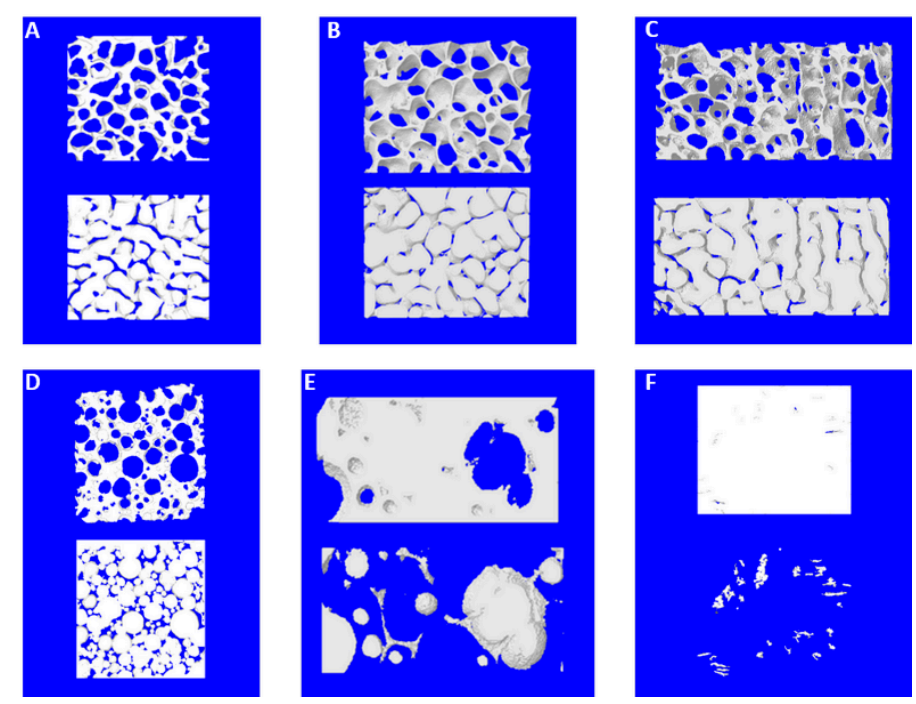

Figure 2. 3D images of selected parts of the samples, each image shows the positive (upper part) and negative (lower part): (A) BioOSS ${ }^{\circledR}, 1 \mathrm{a}$; (B) Biogen ${ }^{\circledR}, 1 \mathrm{~b}$; (C) ICB; (D) ENGIpore ${ }^{\circledR}, 2 \mathrm{~b}$; (E) Bioset, 3a and (F) SINTbone, 4a.

Furthermore, 3D full models were reconstructed as shown in Figure 3. The models, regarding Part 1 and here analyzed again, were reported to allow the comparison among all the samples. The reconstruction of the complete samples let a faster qualitative visualization of the selected biomaterials structural differences.

For the clinical phase, the micro-CT analysis was performed again on the extracted implants. The main morphological results for the selected biomaterials and in reference to the test and control site are indicated in Table 3, including the data previously reported in [33]—specimens $1 \mathrm{a}$ and $2 \mathrm{~b}$.

The percentage variation - the relative difference between the values of each test and control specimen - of the results obtained for the specific parameters (Table 3), evidenced higher values of 
porosity, variation from about $8.7 \%$ for the specimen $2 \mathrm{a}$ test to about $67 \%$ for $3 \mathrm{a}$ test and lower BV/TV, from about $-68.5 \%$ for $3 a$ test to $-8 \%$ for $2 a$ test. The maximum values of porosity were obtained for the $1 \mathrm{~b}$ test and for the $3 \mathrm{a}$ test. The implants related to the biomaterials of bovine origin- $1 \mathrm{a}$ and equine- $1 \mathrm{~b}$ confirmed to have reasonable values of porosity (increments from control to test site about $11 \%-1 \mathrm{a}$ to $16 \%-1 \mathrm{~b}$ ) and BV/TV. Furthermore, for the Tb.Th parameter, higher values were detected from $16.7 \%$ for the $2 b$ test to $50 \%$ for the $1 b$ test and lower values for the $2 a$ test, $-31 \%$, and for the $4 a$ test, $-23.5 \%$.
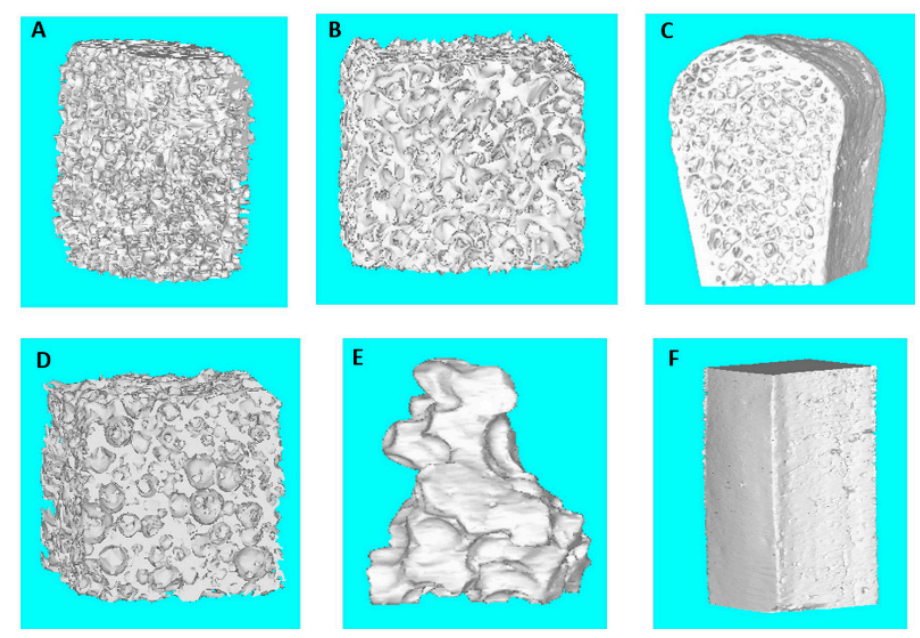

Figure 3. Complete 3D models reconstructed of the biomaterials analyzed in the preclinical phase: (A) BioOSS ${ }^{\circledR}, 1 \mathrm{a}$; (B) Biogen ${ }^{\circledR}, 1 \mathrm{~b}$; (C) ICB; (D) ENGIpore ${ }^{\circledR}$, 2b; (E) Bioset, 3a and (F) SINTbone, 4a. 3.2 Clinical phase: morphological, quantitative and histological results on extracted implants.

Table 3. Morphometrical parameters for each specimen in test and control site implants.

\begin{tabular}{|c|c|c|c|c|c|c|c|}
\hline Group & Label & Implant Site & $\begin{array}{c}\text { BV/TV } \\
(\%)\end{array}$ & $\mathrm{BS} / \mathrm{BV}\left(\mathrm{mm}^{-1}\right)$ & Porosity (\%) & $\begin{array}{l}\text { Tb.Th } \\
(\mu \mathrm{m})\end{array}$ & $\begin{array}{c}\text { Tb.Sp } \\
\left(\mathrm{mm}^{-1}\right)\end{array}$ \\
\hline \multirow{4}{*}{ 1-Bio-bone } & \multirow{2}{*}{$1 \mathrm{a}$} & Test & 19.80 & 95.59 & 80.20 & 0.08 & 0.37 \\
\hline & & Control & 28.17 & 90.22 & 72.20 & 0.06 & 0.22 \\
\hline & \multirow{2}{*}{$1 \mathrm{~b}$} & Test & 10.93 & 39.35 & 89.06 & 0.12 & 0.70 \\
\hline & & Control & 23.15 & 61.21 & 76.85 & 0.08 & 0.28 \\
\hline \multirow{4}{*}{ 2-HA } & \multirow{2}{*}{$2 a$} & Test & 48.05 & 30.50 & 51.95 & 0.11 & 0.19 \\
\hline & & Control & 52.21 & 29.20 & 47.79 & 0.16 & 0.13 \\
\hline & \multirow{2}{*}{$2 b$} & Test & 23.35 & 84.13 & 76.65 & 0.07 & 0.17 \\
\hline & & Control & 39.25 & 81.06 & 60.75 & 0.06 & 0.09 \\
\hline \multirow{2}{*}{ 3-ТCP } & \multirow{2}{*}{$3 a$} & Test & 14.10 & 90.72 & 85.89 & 0.11 & 0.37 \\
\hline & & Control & 44.84 & 45.46 & 51.46 & 0.08 & 0.15 \\
\hline \multirow{2}{*}{ 4-polymer } & \multirow{2}{*}{$4 a$} & Test & 30.99 & 44.15 & 69.01 & 0.13 & 0.27 \\
\hline & & Control & 39.00 & 26.45 & 61.00 & 0.17 & 0.27 \\
\hline
\end{tabular}

Figures 4 and 5 represent the reconstructions for the test and control site of the entire specimen central section and of a selected slice of the same specimen. Density values were associated with various colors to better visualize the structural elements, such as human bone and biomaterials. The color gradient highlights the areas with different mineralization from the yellow-lower mineralization and the orange-medium mineralized structures, to the red color that visualizes highly calcified structures.

About the histological analysis, the images in reference of each selected slice of the specimens-Part 2, investigated in the Part 2 (specimens 1a, 2b, 4a), are shown in Figure 6. 


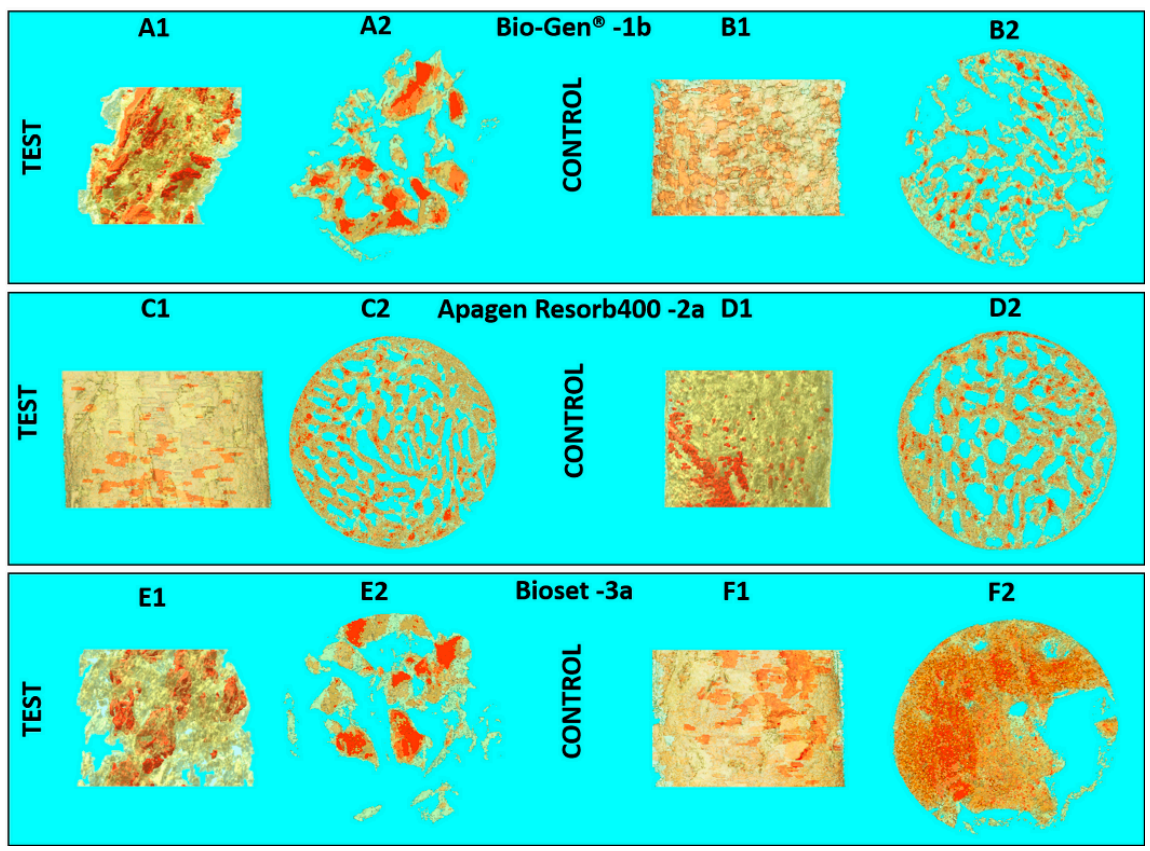

Figure 4. Clinical phase-Part 1, micro-CT reconstructed images for specimens test (left side) and control site (right side): (A1) 1b test, section of the entire specimen; (A2) 1b test, selected slice; (B1) 1b control, section of the entire specimen; (B2) 1b control, selected slice; (C1) 2a test, section of the entire specimen; (C2) 2a test, selected slice; (D1) 2a control, section of the entire specimen; (D2) 2a control, selected slice; (E1) 3a test, section of the entire specimen; (E2) 3a test, selected slice; (F1) 3a control, section of the entire specimen and (F2) 3a control, selected slice.

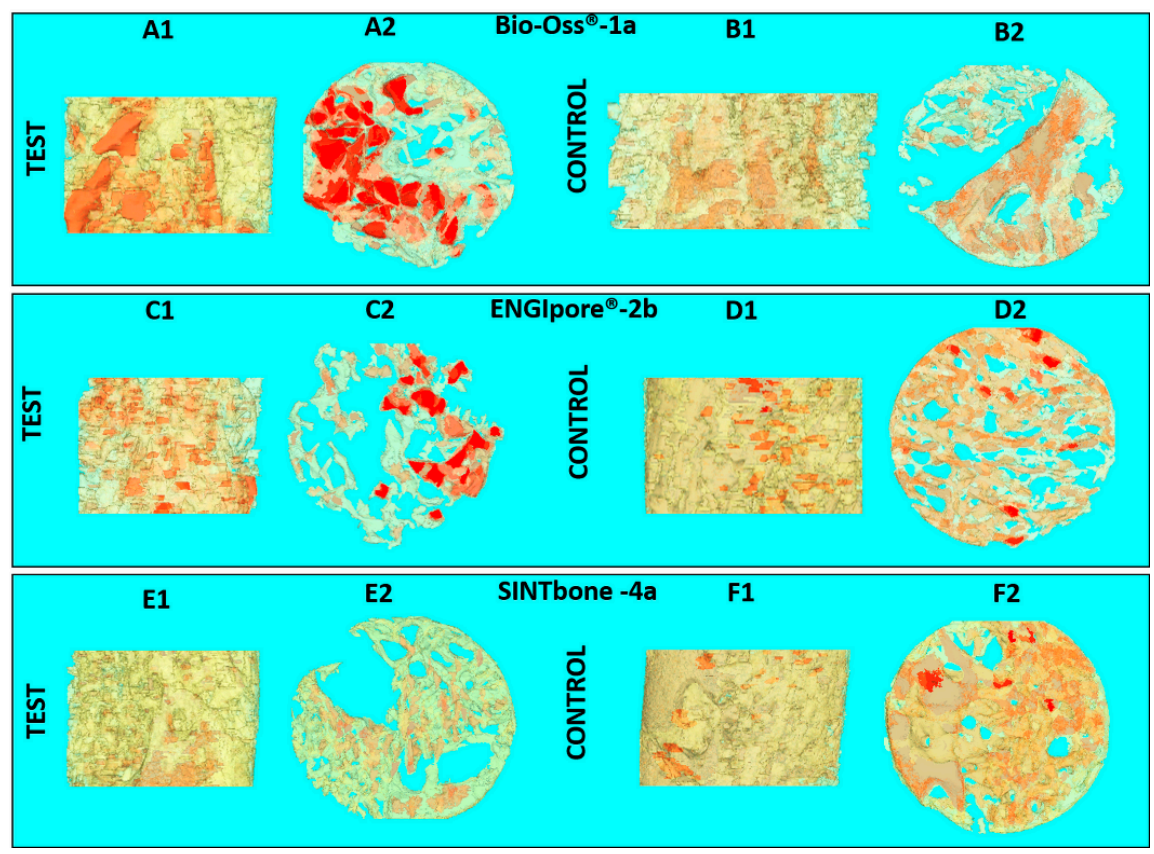

Figure 5. Clinical phase-Part 2, micro-CT reconstructed images for specimens test (left side) and control site (right side): (A1) 1a test, section of the entire specimen; (A2) 1a test, selected slice; (B1) 1a control, section of the entire specimen; (B2) 1a control, selected slice; (C1) 2b test, section of the entire specimen; (C2) 2b test, selected slice; (D1) 2b control, section of the entire specimen; (D2) 2b control, selected slice; (E1) 4a test, section of the entire specimen; (E2) 4a test, selected slice; (F1) 4a control, section of the entire specimen and (F2) 4a control, selected slice. 


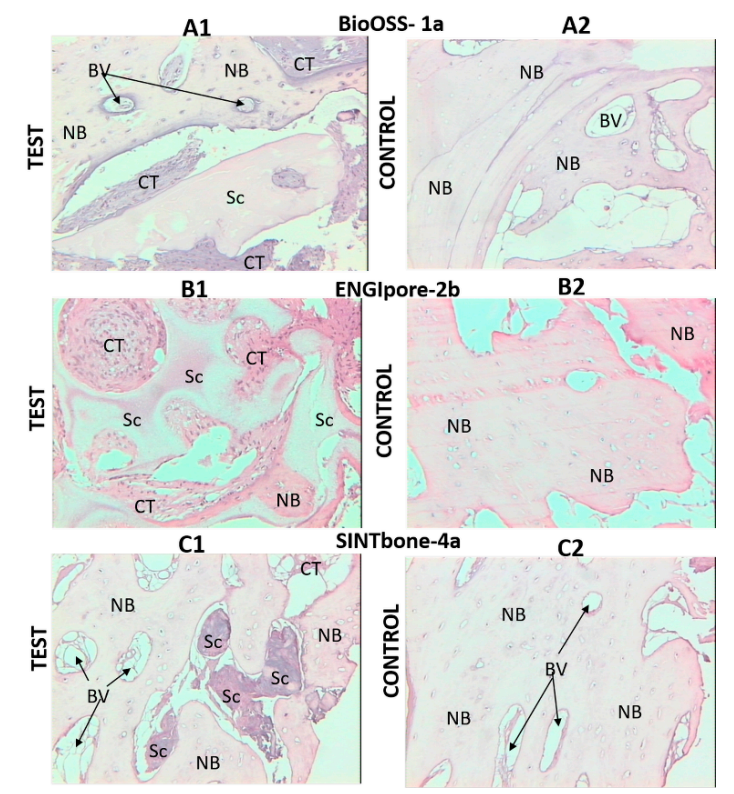

Figure 6. Histology images of specimens test (left side) and control site (right side): (A1) 1a test, entire specimen; (A2) 1a control; (B1) 2b test; (B2) 2b control; (C1) 4a test and (C2) 4a control; Legend: CT = Connective Tissue; $\mathrm{Sc}=$ residual Scaffold; $\mathrm{NB}=$ New Bone; $\mathrm{BV}=$ Blood Vessels.

\section{Discussion}

The structural characterization of the biomaterials is a relevant step for the investigation of the bone substitute properties before implantation and it should be applied to choose the most suitable biomaterial for a specific clinical application.

The porosity is a well-known relevant aspect for scaffolds in bone tissue engineering applications $[2,4,8]$. A high porosity improves the invasion of the graft by progenitor cells. The higher the percentage of pores, the greater the migration of mesenchymal cells and osteoblasts to the recipient site. In addition, a high porosity and a high contact surface-volume ratio, i.e., the presence of many and small pores, promote cell adhesion. At the same time, large pores and the presence of large interconnections among them, improve osteogenesis allowing adequate vascularization. Therefore, an ideal scaffold should have features such as high porosity, a large surface area available for cell adhesion, sufficiently large pores and extensive interconnectivity allowing the penetration of newly formed vascular structures. In the stages following implantation, complex processes of cell migration, differentiation and proliferation occur, which ultimately lead to bone neoformation. The presence of a 3D osteoconductive matrix that has structural characteristics as similar as possible to human bone tissue greatly facilitates the regenerative process [16]. Some authors [4-6] have shown that pores between 100 and $300 \mu \mathrm{m}$ are needed to improve osteogenesis, but large pores could compromise the mechanical strength. This last aspect is relevant at the initial steps of the process as the graft should be able to act like a support of the skeletal segment. From the point of view of the mechanical characteristics of the graft, the size and thickness of the trabeculae are also relevant. Thus, it is necessary to establish a compromise for an optimal performance of the graft on the recipient site.

The iliac crest is the most commonly used extra-oral donor site of autologous bone in the various techniques of bone regeneration [34]. In this study, it was only addressed as a reference at the preclinical phase, before performing the clinical study and without the intention to select the best biomaterial. Preclinical results obtained from the microtomographic analyses (Table 2), showed that the bone substitutes with greater similarities with the human counterpart are the biomaterials of bovine origin-1a and equine-1b. Sufficient porosity and adequate values of BS/BV and Tb.Sp allowed and facilitated entry and migration within the newly formed bone tissue scaffold. At the same time, the BV/TV and the $\mathrm{Tb}$.Th guaranteed mechanical properties comparable to the human bone tissue. The values 
obtained for the two synthetic derivatives, calcium triphosphate, and polylactic-polyglycolic acid, i.e., $3 a$ and $4 a$, evidenced and, confirmed for the $3 a$, that these biomaterials had greater compactness compared to the previous one-2b. In particular, the 4 a sample was characterized by a lower porosity and Tb.Sp, and higher BV/TV; consequently, less space was available for colonization by osteogenic cells and newly formed vessels. Higher interconnection among the internal empty spaces, evidenced in the 3D reconstructed images, is fundamental to be considered for the migration of cells and fluids in the depth of a scaffold; the lower porosity and greater values of the BV/TV and the Tb.Th suggest greater mechanical resistance of these scaffolds. Regarding the results of both parts of the clinical study, in all the examined cases, the specimens of the test site showed a minor compactness with a higher volume of non-mineralized tissue. The evaluation of the percentage variation emphasized the difference between the values of each test and control specimen. The Tb.Sp values were generally higher for the test site specimens, excluding the constant value for the 4a. This last result could be correlated with the lower porosity values obtained, at the preclinical phase, for the corresponding biomaterial (Table 2) and the interconnection observed (Figure 2).

The micro-CT images of Figures 4 and 5 contributed to the numerical data, visualizing the differences among test and control specimens and a uniform comparison of all of them, including the specimens partially investigated in the preliminary works. In the test specimens, the observation underlined the presence of empty spaces, residual biomaterials and not mineralized tissue, like fibrous connective tissue and vascular structures.

The histological images (Figure 6) confirmed the analysis performed by the micro-CT and highlighted some aspects that are hard to discriminate only by the microtomographic observations. Histology allowed identifying the presence of residual biomaterials, as observed by micro-CT, for the specimen 1a, and detecting it in the test specimen of the resorbable polymer (4a test) that, instead, it had not been highlighted by the micro-CT analysis. Moreover, the images showed the presence of different types of non-calcified tissues-fibrous connective tissue, vascular structures, adipose tissue and empty spaces-in some areas that appeared empty in the 3D microtomographic reconstructions.

Therefore, despite limitations in the number of patients enrolled and the types of biomaterials, the results for the analyzed materials suggest less or slower bone neo-formation within the grafted bone defects, as if some biomaterials slow down the process of bone formation, due to limited osteoconductivity [35].

Finally, the obtained results allowed confirming the great potential of the microtomographic investigation and in its combined application with histology. It resulted to be useful to characterize the main significant parameters, to identify the various materials, scaffold traces and the bone tissue structure. Further developments could be oriented to the specific testing of the mechanical properties.

\section{Conclusions}

The study confirmed the great potential of the micro-CT technology for the morphological and structural characterization of biomaterials as bone substitutes for tissue engineering applications in dentistry. The methodology for the assessment was developed and applied at the preclinical and the clinical phase. The clinical study carried out on selected patients and various commercial biomaterials allowed the full analysis of the scaffolds and their interaction with bone tissue. The combined application of the micro-CT with the histology allowed the evaluation of the implants histomorphometric characteristics. The applied investigation process was not focused to identify the best bone substitute but it reached the purpose to improve the methods, for a better quantitative and qualitative assessment. The study should be considered for the investigation of other bone substitutes and for addressing the clinical operators towards the choice of the most suitable biomaterial for a specific clinical application.

Author Contributions: Conceptualization, R.B., R.P., D.M. and I.C.; methodology, R.B., R.P. and D.M.; data curation, R.P. and D.M.; formal analysis and visualization, R.P., D.M. and I.C.; validation-verification, R.B., R.P. and I.C.; writing - original draft preparation, I.C.; writing—review and editing, R.B., R.P. and I.C.; resources, R.B. and D.M; supervision, R.B. All authors have read and agreed to the published version of the manuscript. 
Funding: This research received no external funding.

Acknowledgments: The Authors thank Sapienza University of Rome, the Odontostomatological and Maxillofacial Sciences Department where the clinical investigation was conducted, and Giuseppe Soda of the Experimental Medicine Department for having supported the study with histological analysis.

Conflicts of Interest: The authors declare no conflict of interest.

\section{References}

1. Chocholata, P.; Kulda, V.; Babuska, V. Fabrication of scaffolds for bone-tissue regeneration. Materials 2019, 12, 568. [CrossRef]

2. van Lenthe, G.H.; Hagenmüller, H.; Bohner, M.; Hollister, S.J.; Meinel, L.; Müller, R. Nondestructive micro-computed tomography for biological imaging and quantification of scaffold-bone interaction in vivo. Biomaterials 2007, 28, 2479-2490. [CrossRef] [PubMed]

3. Jones, J.R.; Poologasundarampillai, G.; Atwood, R.C.; Bernard, D.; Lee, P.D. Non-destructive quantitative 3D analysis for the optimisation of tissue scaffolds. Biomaterials 2007, 28, 1404-1413. [CrossRef] [PubMed]

4. Roseti, L.; Parisi, V.; Petretta, M.; Cavallo, C.; Desando, G.; Bartolotti, I.; Grigolo, B. Scaffolds for Bone Tissue Engineering: State of the art and new perspectives. Mater. Sci. Eng. C 2017, 78, 1246-1262. [CrossRef] [PubMed]

5. Mastrogiacomo, M.; Muraglia, A.; Komlev, V.; Peyrin, F.; Rustichelli, F.; Crovace, A.; Cancedda, R. Tissue engineering of bone: Search for a better scaffold. Orthod. Craniofacial Res. 2005, 8, 277-284. [CrossRef]

6. Cao, H.; Kuboyama, N. A biodegradable porous composite scaffold of PGA/ $\beta$-TCP for bone tissue engineering. Bone 2010, 46, 386-395. [CrossRef]

7. Xu, C.; Su, P.; Chen, X.; Meng, Y.; Yu, W.; Xiang, A.P.; Wang, Y. Biocompatibility and osteogenesis of biomimetic Bioglass-Collagen-Phosphatidylserine composite scaffolds for bone tissue engineering. Biomaterials 2011, 32, 1051-1058. [CrossRef]

8. Kim, T.R.; Kim, M.S.; Goh, T.S.; Lee, J.S.; Kim, Y.H.; Yoon, S.Y.; Lee, C.S. Evaluation of structural and mechanical properties of porous artificial bone scaffolds fabricated via advanced TBA-based freeze-gel casting technique. Appl. Sci. 2019, 9, 1965. [CrossRef]

9. Chen, Q.Z.; Thompson, I.D.; Boccaccini, A.R. 45 S5 Bioglass ${ }^{\circledR}$-derived glass-ceramic scaffolds for bone tissue engineering. Biomaterials 2006, 27, 2414-2425. [CrossRef]

10. Thavornyutikarn, B.; Chantarapanich, N.; Sitthiseripratip, K.; Thouas, G.A.; Chen, Q. Bone tissue engineering scaffolding: Computer-aided scaffolding techniques. Prog. Biomater. 2014, 3, 61-102. [CrossRef]

11. Chen, Q.Z.; Li, Y.; Jin, L.Y.; Quinn, J.M.W.; Komesaroff, P.A. A new sol-gel process for producing $\mathrm{Na}_{2} \mathrm{O}$-containing bioactive glass ceramics. Acta Biomater. 2010, 6, 4143-4153. [CrossRef] [PubMed]

12. Groll, J.; Boland, T.; Blunk, T.; Burdick, J.A.; Cho, D.W.; Dalton, P.D.; Derby, B.; Forgacs, G.; Li, Q.; Mironov, V.A.; et al. Biofabrication: Reappraising the definition of an evolving field. Biofabrication $2016,8$. [CrossRef] [PubMed]

13. Tamjid, E.; Bohlouli, M.; Mohammadi, S.; Alipour, H.; Nikkhah, M. Sustainable drug release from highly porous and architecturally engineered composite scaffolds prepared by 3D printing. J. Biomed. Mater. Res. Part A 2020, 108, 1426-1438. [CrossRef] [PubMed]

14. Lee, J.-Y.; Choi, B.; Wu, B.; Lee, M. Customized biomimetic scaffolds created by indirect three-dimensional printing for tissue engineering. Biofabrication 2013, 5, 045003. [CrossRef] [PubMed]

15. Zou, F.; Jiang, J.; Lv, F.; Xia, X.; Ma, X. Preparation of antibacterial and osteoconductive 3D-printed PLGA/Cu(I)@ZIF-8 nanocomposite scaffolds for infected bone repair. J. Nanobiotechnology 2020, 18, 39. [CrossRef]

16. Pecci, R.; Baiguera, S.; Ioppolo, P.; Bedini, R.; Del Gaudio, C. 3D printed scaffolds with random microarchitecture for bone tissue engineering applications: Manufacturing and characterization. J. Mech. Behav. Biomed. Mater. 2020, 103, 103583. [CrossRef]

17. Denry, I.; Kuhn, L.T. Design and characterization of calcium phosphate ceramic scaffolds for bone tissue engineering. Dent. Mater. 2016, 32, 43-53. [CrossRef]

18. Traini, T.; Piattelli, A.; Caputi, S.; Degidi, M.; Mangano, C.; Scarano, A.; Perrotti, V.; Iezzi, G. Regeneration of human bone using different bone substitute biomaterials. Clin. Implant Dent. Relat. Res. 2015, 17, 150-162. [CrossRef] 
19. Bai, Y.; Sha, J.; Kanno, T.; Miyamoto, K.; Hideshima, K.; Matsuzaki, Y. Comparison of the Bone Regenerative Capacity of Three-Dimensional Uncalcined and Unsintered Hydroxyapatite/Poly-d/l-Lactide and Beta-Tricalcium Phosphate Used as Bone Graft Substitutes. J. Investig. Surg. 2019, 1-14. [CrossRef]

20. Sha, J.; Kanno, T.; Miyamoto, K.; Bai, Y.; Hideshima, K.; Matsuzaki, Y. Application of a Bioactive/Bioresorbable Three-Dimensional Porous Uncalcined and Unsintered Hydroxyapatite/Poly-D/L-lactide Composite with Human Mesenchymal Stem Cells for Bone Regeneration in Maxillofacial Surgery: A Pilot Animal Study. Materials 2019, 12, 705. [CrossRef]

21. Annibali, S.; Bellavia, D.; Ottolenghi, L.; Cicconetti, A.; Cristalli, M.P.; Quaranta, R.; Pilloni, A. Micro-CT and PET analysis of bone regeneration induced by biodegradable scaffolds as carriers for dental pulp stem cells in a rat model of calvarial "critical size" defect: Preliminary data. J. Biomed. Mater. Res. B Appl. Biomater. 2014, 102, 815-825. [CrossRef] [PubMed]

22. Barboni, B.; Mangano, C.; Valbonetti, L.; Marruchella, G.; Berardinelli, P.; Martelli, A.; Muttini, A.; Mauro, A.; Bedini, R.; Turriani, M.; et al. Synthetic bone substitute engineered with amniotic epithelial cells enhances bone regeneration after maxillary sinus augmentation. PLoS ONE 2013, 8, e63256. [CrossRef] [PubMed]

23. Yeo, A.; Cheok, C.; Teoh, S.H.; Zhang, Z.Y.; Buser, D.; Bosshardt, D.D. Lateral ridge augmentation using a PCL-TCP scaffold in a clinically relevant but challenging micropig model. Clin. Oral Implants Res. 2012, 23, 1322-1332. [CrossRef] [PubMed]

24. Turnbull, G.; Clarke, J.; Picard, F.; Riches, P.; Jia, L.; Han, F.; Li, B.; Shu, W. 3D bioactive composite scaffolds for bone tissue engineering. Bioact. Mater. 2018, 3, 278-314. [CrossRef]

25. Lei, B.; Guo, B.; Rambhia, K.J.; Ma, P.X. Hybrid polymer biomaterials for bone tissue regeneration. Front. Med. 2019, 13, 189-201. [CrossRef]

26. Barbetta, A.; Bedini, R.; Pecci, R.; Dentini, M. Role of X-ray microtomography in tissue engineering. Ann. Ist. Super. Sanità 2012, 48, 10-18.

27. Grande, N.M.; Plotino, G.; Gambarini, G.; Testarelli, L.; D’Ambrosio, F.; Pecci, R.; Bedini, R. Present and future in the use of micro-CT scanner 3D analysis for the study of dental and root canal morphology. Ann. Ist. Super. Sanita 2012, 48, 26-34.

28. Campioni, I.; Cacciotti, I.; Gupta, N. Additive manufacturing of reconstruction devices for maxillofacial surgery: Design and accuracy assessment of a mandibular plate prototype. Ann. Ist. Super. Sanità 2020, 56, 10-18.

29. Irie, M.S.; Rabelo, G.D.; Spin-Neto, R.; Dechichi, P.; Borges, J.S.; Soares, P.B.F. Use of Micro-Computed Tomography for Bone Evaluation in Dentistry. Braz. Dent. J. 2018, 29, 227-238. [CrossRef]

30. Bedini, R.; Pecci, R.; Marinozzi, F.; Bini, F.; Rizzo, G.; Campioni, I. Valutazione Morfometrica e Strutturale Della Architettura del Tessuto Osseo Trabecolare del Collo del Femore: Analisi Microtomografica; Istituto Superiore di Sanità: Roma, Italy, 2018; Volume 18/7, Rapporti ISTISAN; Available online: http://old.iss.it/binary/publ/ cont/18_7_web.pdf (accessed on 15 April 2020).

31. Bedini, R.; Meleo, D.; Pecci, R. 3D microtomography characterization of dental implantology bone substitutes used in-vivo. Key Eng. Mater. 2013, 541, 97-113. [CrossRef]

32. Meleo, D.; Bedini, R.; Pecci, R.; Mangione, F.; Pacifici, L. Microtomographic and morphometric characterization of a bioceramic bone substitute in dental implantology. Ann. Ist. Super. Sanita 2012, 48, 59-64. [PubMed]

33. Bedini, R.; Meleo, D.; Pecci, R. Role of Benchtop Microtomographic Systems in Tissue Engineering. In Advanced High-Resolution Tomography in Regenerative Medicine; Giuliani, A., Cedola, A., Eds.; Fundamental Biomedical Technologies; Springer International Publishing: Cham, Switzerland, 2018; pp. 41-50. ISBN 978-3-030-00367-8.

34. Idrontino, G.; Valente, N.A. Intraoral and extraoral autologous bone block graft techniques: A review of the recent literature. Int. J. Contemp. Dent. Med. Rev. 2016, 2016.

35. Sanz, M.; Dahlin, C.; Apatzidou, D.; Artzi, Z.; Bozic, D.; Calciolari, E.; De Bruyn, H.; Dommisch, H.; Donos, N.; Eickholz, P.; et al. Biomaterials and regenerative technologies used in bone regeneration in the craniomaxillofacial region: Consensus report of group 2 of the 15th European Workshop on Periodontology on Bone Regeneration. J. Clin. Periodontol. 2019, 46, 82-91. [CrossRef] [PubMed]

(C) 2020 by the authors. Licensee MDPI, Basel, Switzerland. This article is an open access article distributed under the terms and conditions of the Creative Commons Attribution (CC BY) license (http://creativecommons.org/licenses/by/4.0/). 